\title{
Acceleration of ventricular response to atrial flutter after intravenous adenosine
}

\author{
A C Rankin, A P Rae, A Houston
}

\begin{abstract}
Adenosine may be of therapeutic and diagnostic value in the emergency management of arrhythmias. It causes transient atrioventricular nodal block and thus ends paroxysmal supraventricular tachycardias that involve the atrioventricular node. Also, it may uncover underlying atrial arrhythmias by slowing the ventricular response. Its duration of action is brief and serious adverse effects have not been reported. A 12 year old patient with atrial flutter is presented, in whom intravenous adenosine was followed by acceleration of the heart rate to a potentially dangerous arrhythmia.
\end{abstract}

(Br Heart f 1993;69:263-265)

Adenosine is an endogenous purine nucleoside that causes atrioventricular nodal block when injected intravenously. ${ }^{12}$ It is effective, therefore, to end paroxysmal supraventricular tachycardias that have a re-entrant circuit that includes the atrioventricular node. ${ }^{3-6}$ With atrial arrhythmias, such as atrial flutter, adenosine induced atrioventricular nodal block may be of diagnostic value by slowing the ventricular response to show the underlying atrial tachyarrhythmia. ${ }^{3-5}$ Transient side effects, including chest discomfort, flushing, and dyspnoea, are common, but serious adverse effects of adenosine have not been reported. This may be attributable to its extreme brevity of action because of rapid metabolism and removal from blood. ${ }^{7} \mathrm{We}$ report a case where intravenous administration of adenosine was followed by an increase in the ventricular response to atrial flutter, with a resultant potentially life threatening arrhythmia.

\section{Case report}

A 12 year old boy was admitted to hospital after an episode of syncope. He had a history of Mustard repair of transposition of the great arteries at the age of 10 months. After the repair of an atrial baffle leak one year before the present admission, he had undergone implantation of a permanent ventricular pacemaker (Medtronic "Activitrax II", VVI-R) for symptomatic sinus node dysfunction. He had continued to complain of episodes of dizziness, the aetiology of which was not identified.

On admission he was well with no evidence of heart failure. Heart rate was 120 beats/min and he was normotensive, with a blood pres- sure of 109/58 mm Hg. An electrocardiogram showed a narrow complex tachycardia. To clarify the diagnosis of the tachycardia, and possibly restore normal rhythm, adenosine was given intravenously with incremental boluses of $0.1,0.2$, and $0.4 \mathrm{mg} / \mathrm{kg}(4,8$, and $16 \mathrm{mg}$ ). Transient symptoms of increasing severity (flushing, non-specific malaise) were reported with each dose. After the $8 \mathrm{mg}$ dose of adenosine, the ventricular rate briefly slowed to 86 beats/min (for four seconds) but then increased to 235 beats $/ \mathrm{min}$. This rapid rate persisted for three minutes before settling to 120 beats $/ \mathrm{min}$. A further dose $(16 \mathrm{mg})$ was given. This slowed the ventricular rate so that the pacemaker paced the ventricle at 60 beats/min for 10 seconds (fig $1 \mathrm{~A}$ ). During this period of ventricular slowing, underlying atrial flutter waves at 280 beats/min were apparent. The ventricular response then accelerated, to 140 beats/min (2:1 atrial to ventricular conduction) for five seconds, and then to 240 beats/min ( $1: 1$ conduction) for one minute (fig $1 \mathrm{C}$ ), before settling to 130 beats/min. The patient's clinical condition transiently deteriorated during the periods of very fast heart rate, but improvement occurred as the rate settled.

The patient then remained stable, with a heart rate of 120 beats $/ \mathrm{min}$. The next day, he was allowed to get up, with ambulatory Holter monitoring of his cardiac rhythm. He suddenly collapsed with loss of consciousness and cardiopulmonary resuscitation was initiated. Cardiac rhythm was found to be ventricular fibrillation from which he was defibrillated after multiple DC shocks. Analysis of the Holter recording showed that the cardiac rhythm before the cardiac arrest was atrial flutter with $2: 1$ atrioventricular conduction that changed to $1: 1$ conduction, causing the ventricular rate to abruptly increase from 125 to 250 beats/min (fig 2). This arrhythmia degenerated into ventricular fibrillation.

At subsequent electrophysiological study atrial flutter was induced during catheter manipulation. The atrioventricular response was initially $2: 1$, with a ventricular rate of 120 beats/min, but acceleration to $1: 1$ conduction with a ventricular rate of 240 beats $/ \mathrm{min}$ caused hypotension and respiratory arrest. Atrial flutter was terminated by atrial overdrive pacing. There was no evidence of an accessory pathway. Drug treatment with amiodarone and digoxin later controlled the ventricular response during atrial flutter.
Correspondence to Dr A C Rankin, University Cardiology, Royal Infirmary 10 Alexandra Parade, Glasgow G31 2ER. 
Figure 1 Effects of adenosine on ventricular response to atrial flutter. (A) 10 s after the intravenous administration of $16 \mathrm{mg}$ adenosine, the ventricular rate slowed from 120 beats/minute and ventricular pacing at 60 beats/min occurred. Underlying atrial flutter waves were evident. (B) After ventricular pacing for $10 \mathrm{~s}, 2: 1$ atrioventricular conduction resumed with a ventricular response of 130 beats/min. (C) The ventricular response then increased until, at one minute, ventricular rate was 240 beats/min, with 1:1 atrioventricular conduction. Lead II, paper speed $25 \mathrm{~mm} / \mathrm{s}$.

A

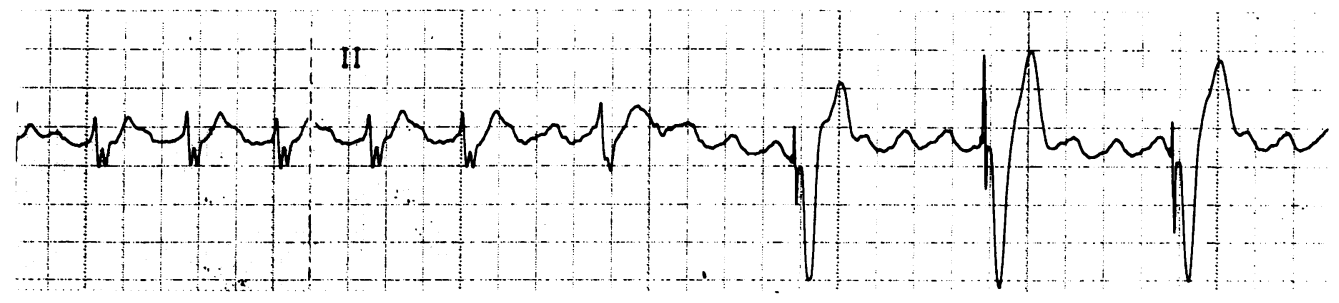

B

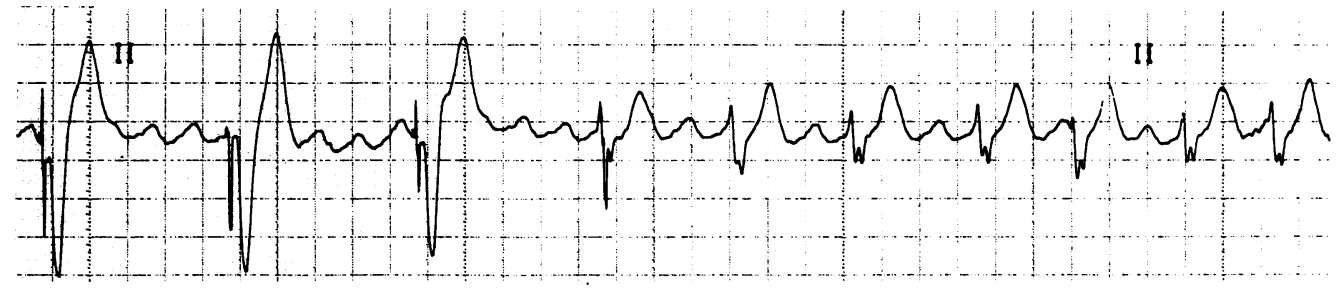

C

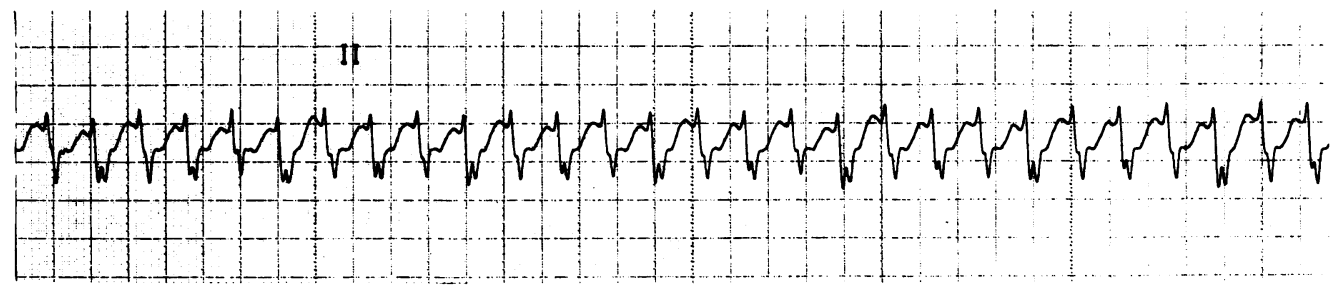

15

\section{Discussion}

Adenosine has been used to successfully treat paroxysmal supraventricular tachycardia in hundreds of patients, including infants and children. ${ }^{5}$ Also, it has proved to be of value in the diagnosis of both narrow and broad complex tachycardias. ${ }^{3-58}$ No serious adverse effects have been reported. The direct cardiac action of adenosine is to cause slowing of heart rate, both by reducing the sinus rate and by causing atrioventricular nodal block. ${ }^{29}$ Bradycardia, including ventricular standstill of several seconds duration, has been reported, but normal rhythm was rapidly restored without long-term adverse effects. ${ }^{34}$ Ventricular pacing prevented substantial bradycardia in the present case, but the adenosine induced slowing was followed by a
A

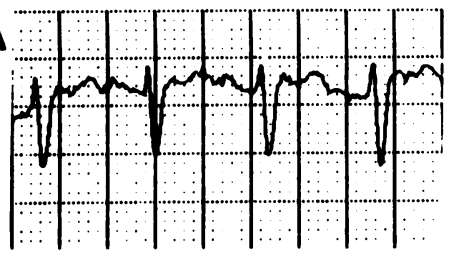

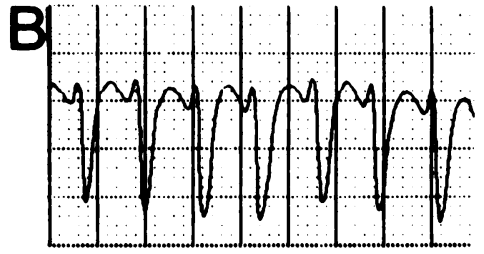

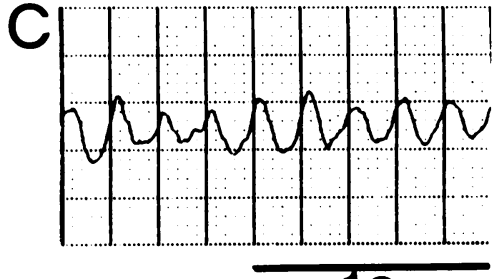

is

D

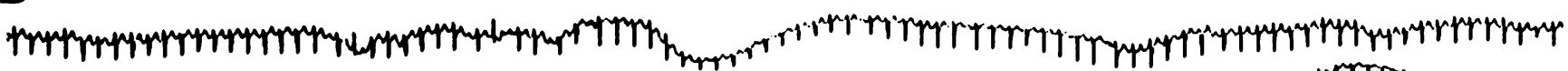

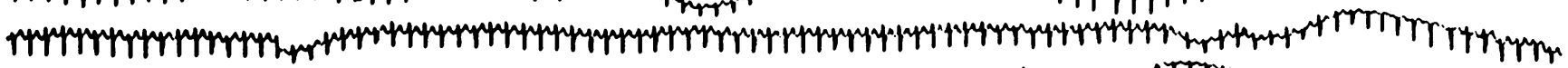

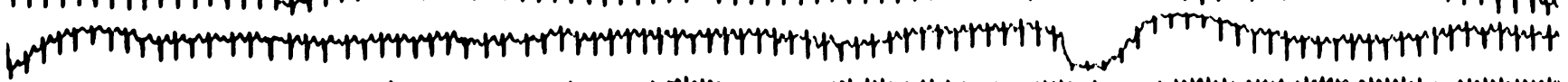

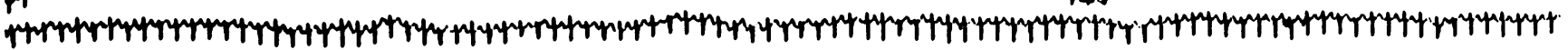

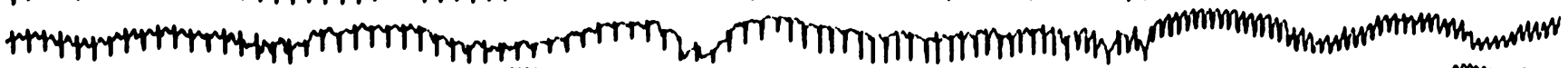

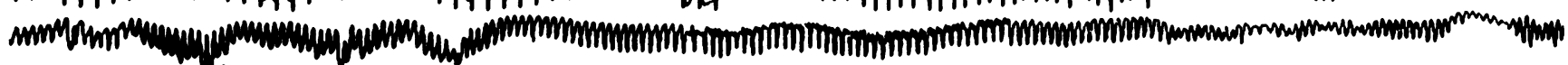

Figure 2 Ambulatory monitoring of cardiac rhythm before cardiac arrest. (A) Atrial flutter with 2:1 atrioventricular response and a ventricular rate of 120 beats/min. (B) Ventricular rate increased to 240 beats/min, due to 1:1 conduction. (C) Degeneration of rapid ventricular rhythm into ventricular fibrillation. (D) Full disclosure of the recording showing the rapid degeneration into ventricular fibrillation after the onset of the 1:1 atrioventricular response. 
dangerous acceleration of ventricular rate, probably secondary to sympathetic nerve activation. ${ }^{10}$ That this arrhythmia was potentially life threatening was shown when a similar acceleration of rate subsequently recurred spontaneously and resulted in cardiac arrest.

Transient increase in heart rate after adenosine induced bradycardia has been previously reported..$^{911} 12$ Intravenous boluses of adenosine during sinus rhythm caused transient slowing of ventricular rate, due to sinus bradycardia and second degree heart block lasting for only a few beats, which was followed by sinus tachycardia of about one minute duration. This tachycardia was associated with respiratory stimulation, was found after adenosine injection in the aortic arch, but not the descending aorta, and was absent in patients with autonomic failure. ${ }^{12}$ These findings suggested that the tachycardia is mediated by the sympathetic nervous system, secondary to stimulation by adenosine of chemoreceptors in the carotid body. This has been supported by direct evidence of adenosine induced increases in sympathetic tone. ${ }^{10}$ Additional factors that may contribute to an increase in heart rate are the unpleasant side effects of adenosine that many patients experience, and its vasodilating action. The therapeutic and diagnostic values of adenosine are due to its direct negative dromotropic action, but this case shows that the secondary positive chronotropic action may result in adverse effects.

The potential for atrial flutter to suddenly double the ventricular rate, with an increase in atrioventricular conduction from $2: 1$ to $1: 1$, may explain its association with cardiac arrest, particularly in children with congenital heart disease. ${ }^{1314}$ Atrial flutter has been noted as a common arrhythmia after Mustard repair of transposition of the great arteries, and is associated with sudden death. ${ }^{15}$ The present case indicates that adenosine may have an adverse effect in such patients because of enhanced atrioventricular conduction secondary to sympathetic activation. In patients with Wolff-Parkinson-White syndrome, in whom sympathetic stimulation may enhance conduction through an accessory pathway, adenosine has been shown to increase the ventricular response to rapid atrial pacing, from $2: 1$ to $1: 1$ atrioventricular conduction. ${ }^{16}$ A similar effect on atrioventricular nodal conduction, secondary to sympathetic activation, would explain the findings in the present case.

The absence of reported serious adverse effects attributable to intravenous adenosine is likely to be due to its brevity of action. It could be argued that in the present case the adenosine related increase in heart rate was also transient with no long-term sequelae. This same increase in heart rate had, however, near fatal consequences on two subsequent occasions, and it must therefore be acknowledged that adenosine was associated with the production of a potentially fatal arrhythmia. This case emphasises the importance of ensuring that facilities for resuscitation, including DC cardioversion, are available when adenosine is given to patients with tachycardias, especially children with congenital heart disease and possible atrial flutter.

1 Honey RM, Rithchie WT, Thomson WAR. The action of adenosine upon the human heart. Of Med 1930;23: adenosin

2 Favale S, DiBiase M, Rizzo U, Belardinelli L, Rizzon P. Effect of adenosine and adenosine-5-triphosphate on atrioventricular conduction in patients. $\mathcal{F} \mathrm{Am}$ Coll Cardiol 1985;5:1212-9.

3 DiMarco JP, Sellers TD, Lerman BB, Greenberg ML, Berne RM, Belardinelli L. Diagnostic and therapeutic use of adenosine in patients with supraventricular tachyarrhythmias. $f \mathrm{Am}$ Coll Cardiol 1985;6:417-8.

4 Rankin AC, Oldroyd KG, Chong E, Rae AP, Cobbe SM. Value and limitations of adenosine in the diagnosis and treatment of narrow and broad complex tachycardias. treatment of narrow and broad

5 Till J, Shinebourn EA, Rigby ML, Clarke B, Ward DE, Rowland E. Efficacy and safety of adenosine in the treatment of supraventricular tachycardia in infants and children. Br Heart $\mathcal{F}$ 1989;62:204-11.

6 DiMarco JP, Miles W, Akhtar M, et al. Adenosine for paroxysmal supraventricular tachycardia: dose ranging and comparison with verapamil. Ann Intern Med 1990;113:104-10

7 Moser GH, Schrader J, Deussen A. Turnover of adenosine in plasma of human and dog blood. Am $\mathcal{f}$ Physiol 1989;256:C799-C806.

8 Griffith MJ, Linker NJ, Ward DE, Camm AJ. Adenosine in the diagnosis of broad complex tachycardia. Lancet 1988;i:672-5.

9 DiMarco JP, Sellars TD, Berne RM, West GA, Belardinelli $L$. Adenosine: electrophysiologic effects and therapeutic use for terminating paroxysmal supraventricular tachycardia. Circulation 1983;68:1254-63.

10 Biaggioni I, Killian TJ, Mosqueda-Garcia R, Robertson RM, Robertson D. Adenosine increases sympathetic nerve traffic in humans. Circulation 1991;83:1668-75.

11 Watt AH, Routledge PA. Transient bradycardia and subsequent sinus tachycardia produced by intravenous adenosine in healthy adult subjects. $\mathrm{Br} \mathcal{F}$ Clin Pharmacol 1986;21:533-6.

12 Biaggioni I, Olafsson B, Robertson RM, Hollister AS, Robertson D. Cardiovascular and respiratory effects of adenosine in conscious man. Evidence for chemoreceptor activation. Circ Res 1987;61:779-86.

13 Garson A, Blink-Boelkens M, Hesslein PS, Hordof AJ, Keane JF, Neches WH, Porter CJ. Atrial flutter in the Keane JF, Neches WH, Porter CJ. Atrial flutter in the
young: a collaborative study in 380 cases. $\mathcal{F ~} \mathrm{Am}$ Coll young: a collaborative

14 Silka MJ, Kron J, Walance CG, Cutler JE, McAnulty JH. Assessment and follow-up of pediatric survivors of sudden cardiac death. Circulation 1990;82:341-9.

15 Flinn CJ, Wolff GS, Dick M, et al. Cardiac arrhythmias after Mustard operation for complete transposition of the great arteries. $N$ Engl $\mathcal{F}$ Med 1984;310:1635-8.

16 Garratt CJ, Griffith MJ, O'Nunain S, Ward DE, Camm AJ. Effects of intravenous adenosine on antegrade refractoriness of accessory atrioventricular connections. Circulation 1991;84:1962-8. 